\title{
Doctors of BC will vote again for president-elect
}

$\mathrm{D}$

octors of $\mathrm{BC}$ will hold a second election to determine who will lead the provincial association in 2016, after a recount showed that an earlier vote was tied.

Rural family physician Dr. Alan Ruddiman lost the initial May 26 election by a single vote to Dr. Brian Day, a private clinic owner who is currently embroiled in a constitutional challenge that may set the precedent for two-tier health care in Canada.

Day's narrow win stirred debate about the future of public health care in British Columbia, and some questioned the validity of the vote given that less than $20 \%$ of eligible doctors participated.

At Ruddiman's request, Doctors of $\mathrm{BC}$ conducted a recount which showed that the two candidates were actually tied. "One vote that ought to have been counted was in fact not counted," explained Chief Electoral Officer and CEO Allan Seckel in a June 1 statement.

A run-off election between Ruddiman and Day will now take place June 5-18. All members in good standing who are eligible to vote can participate. — Lauren Vogel, CMAJ

CMAJ 2015. DOI:10.1503/cmaj.109-5085

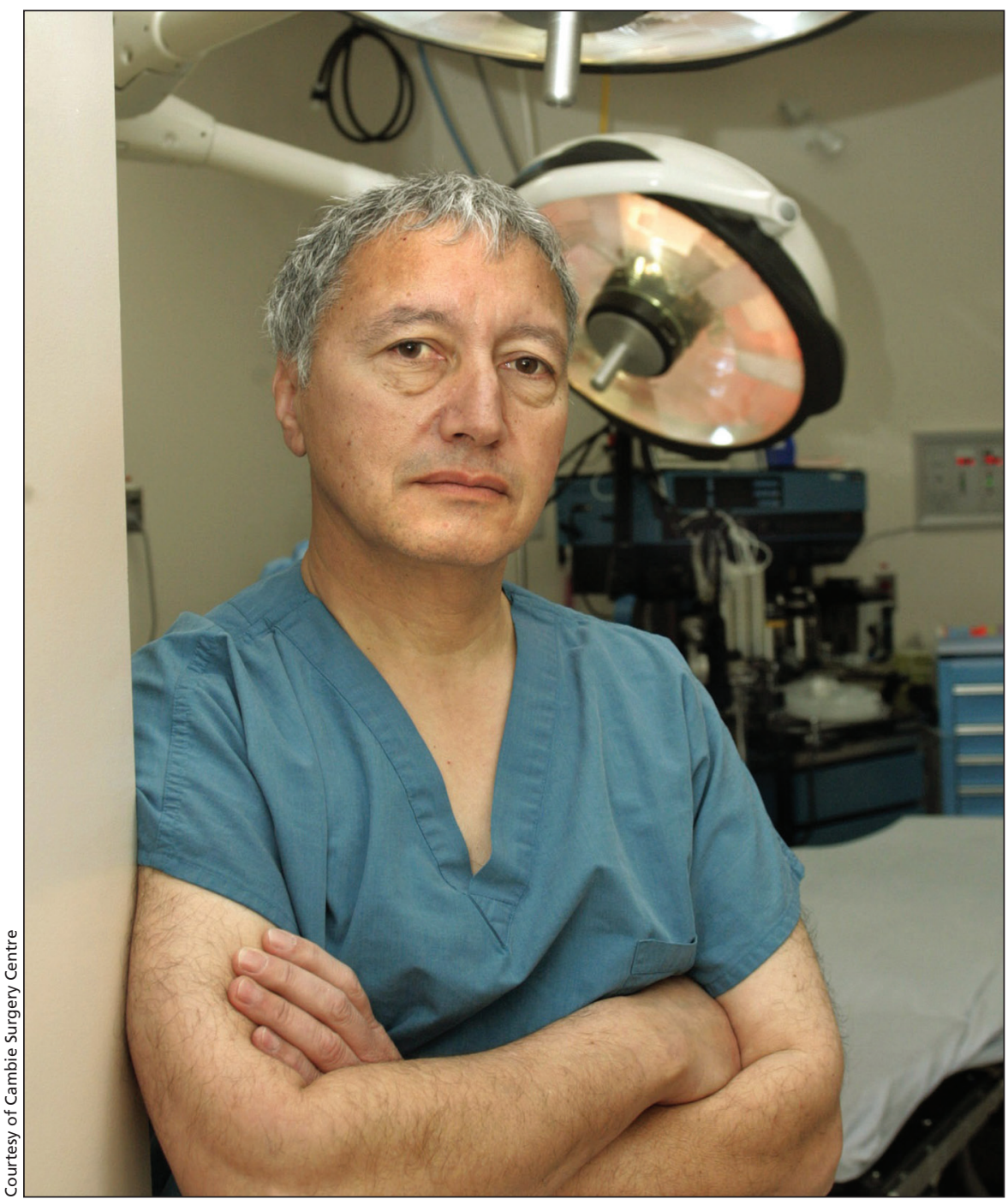

Doctors of BC will hold a run-off vote for president-elect. Candidates Dr. Brian Day (pictured) and Dr. Alan Ruddiman tied in an initial vote. 